
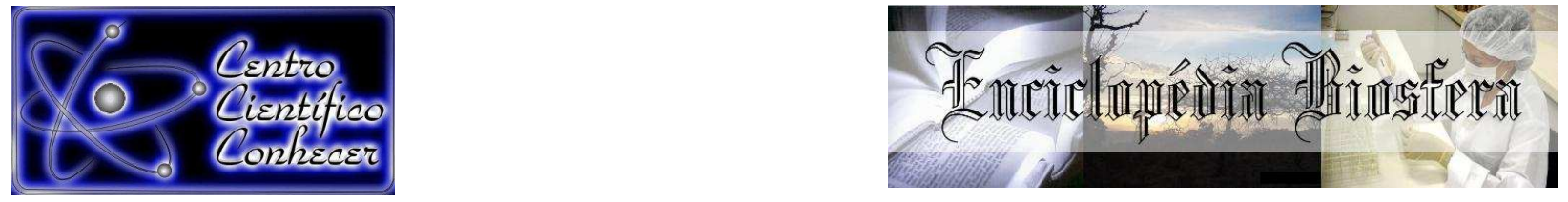

\title{
VIABILIDADE DA APLICAÇÃO DE PRODUTO CORRETIVO DA ACIDEZ DO SOLO VIA ÁGUA DE IRRIGAÇÃO
}

\author{
Jorge Alcântara Espíndola Cardoso ${ }^{1}$, Ricardo Alexandre Lambert ${ }^{2}$, Aldaisa Martins \\ da Silva de Oliveira ${ }^{3}$
}

1.Graduado em Agronomia pela Universidade Luterana do Brasil

(jorge gt.ba@hotmail.com), Itumbiara, Brasil

2. Professor Doutor da Universidade Luterana do Brasil, Itumbiara, Brasil

3.Professora Mestre da Universidade Luterana do Brasil, Itumbiara, Brasil

\section{Recebido em: 03/10/2016 - Aprovado em: 21/11/2016 - Publicado em: 05/12/2016 \\ DOI: 10.18677/EnciBio_2016B_102}

\begin{abstract}
O Brasil apresenta potencial ao cultivo de diversas culturas, todavia, sua produtividade tem se mostrado inferior à capacidade, isso devido a problemas nutricionais e à disponibilidade hídrica deficitária. A acidez do solo pode comprometer a eficiência nas adubações, sendo necessário corrigir o pH edáfico para nutrir adequadamente as plantas. A correção da acidez é geralmente feita pela calagem, entretanto sua aplicação à fruticultura é dificultada, pois a eficiência da aplicação é intrínseca à incorporação do corretivo ao solo. Assim a calagem somente é viável antes da implantação do pomar, haja vista que após a instalação das mudas, torna-se impraticável a incorporação mecânica. Entretanto para culturas perenes recomenda-se aplicar corretivo durante o desenvolvimento vegetal, sendo necessária adotar técnicas para incorporação do corretivo sem danos às raízes. Neste contexto a aplicação do corretivo via irrigação é uma técnica promissora, pois a própria lâmina d'água aplicada promoverá a incorporação. Todavia as espécies químicas dos corretivos têm alto potencial à precipitação e sedimentação, podendo ocasionar entupimento dos emissores, refletindo no aumento de pressão na linha de irrigação e redução da uniformidade de distribuição do sistema. Neste sentido objetivou-se avaliar quatro tipos de corretivos considerando-se cinco tempos de amostragem dispostos em um ensaio de bancada em DIC fatorial, afim de estudar a uniformidade de aplicação do sistema de irrigação pelo monitoramento do CUC e da pressão na linha de irrigação. Mesmo sob os aspectos negativos desta metodologia, atestou-se positivamente a eficiência de sua aplicação, porém a injeção de doses recomendadas pode levar muito tempo.
\end{abstract}

RESUMO

PALAVRAS-CHAVE: fruticultura, $\mathrm{pH}$ edáfico, uniformidade.

\section{VIASIBILITY OF APPLICATION OF CONCEALER PRODUCT OF THE ACIDITY OF THE SOIL VIA IRRIGATION WATER}

\footnotetext{
ABSTRACT

Brazil offers the potential for cultivation of different crops, however, the productivity has been shown below the capacity, this is due to nutritional problems and deficient water availability. The acidity of the soil can compromise efficiency in fertilization, therefore, it is necessary to correct the $\mathrm{pH}$ of the edaphic environment to nourish the plants. The acidity correction is usually done by liming, however, its application to fruit-growing is difficult, because the efficiency of the application is intrinsic to ENCICLOPÉDIA BIOSFERA, Centro Científico Conhecer - Goiânia, v.13 n.24; p.1079 2016
} 
incorporation of the corrective on the soil. Thus, the liming is only feasible prior to implantation of the orchard, considering that after installation of the seedlings, it becomes impractical to incorporate mechanically. However, for perennial crops it is recommended to apply corrective during the period that the plants are installed, it is necessary to adopt techniques for embedding the corrective without damaging the roots. In this context, the application of corrective via irrigation is a promising technique, because the sheet of water applied will promote the embedding. However, the chemical species of correctives has a high potential for precipitation and sedimentation and can cause clogging of emitters, reflecting on increased pressure on irrigation line and a decrease of distribution uniformity of the system. In this way aims evaluate four kinds of correctives, considering five time of sampling arranged in bench experiment in factorial DIC, objectifying study the application uniformity of the irrigation system by monitoring of the "CUC" and pressure on the irrigation line. Even under the negative aspects of this methodology, testified positively the efficiency of this application, but the injection of recommended doses can take a long time.

KEYWORDS: Edaphic $\mathrm{pH}$, fruit-growing, uniformity.

\section{INTRODUÇÃO}

O Brasil possui em toda sua extensão, condições edafoclimáticas adequadas ao cultivo de diversas culturas, desde culturas anuais até as culturas perenes, como as frutíferas, entretanto, mesmo com todo este potencial produtivo, a produtividade do país tem se mostrado muito inferior à sua capacidade, isso se deve em grade parte a problemas relacionados à nutrição e à disponibilidade hídrica deficitária.

Os solos Brasileiros agricultáveis são em sua grande maioria ácidos, característica que o conferem baixa disponibilidade de nutrientes como cálcio $(\mathrm{Ca})$, magnésio $(\mathrm{Mg})$ e potássio $(\mathrm{K})$, assim um melhor controle na zona radicular das plantas, se torna fundamental para a adequação do equilíbrio nutricional para os vegetais. Deste modo a correção da acidez do solo se destaca como um método necessário e eficiente para a manutenção desse equilíbrio, podendo ser facilmente realizada por meio da adição de produtos corretivos deste caráter, como o calcário, e a cal hidratada (FRANCHINI et al., 2001 citado por PESSONI, 2009).

O calcário é atualmente o produto corretivo da acidez mais difundido, sendo este adotado pela maioria dos agricultores, no entanto, a eficiência de sua aplicação está condicionada à incorporação deste insumo ao solo, tornando esta prática inconveniente para aplicação em cultivos frutícolas, pois os pomares quando já estabelecidos não permitem incorporação do material corretivo, principalmente nas regiões mais próximas ao caule, e mais especificamente na região da rizosfera, pois tal tarefa poderia ocasionar o dilaceramento das raízes.

Outro aspecto importante é a disponibilidade de água, a distribuição pluvial na região do Cerrado, que é um local com grande ocorrência de solos ácidos, é bem definida em dois estágios (inverno e verão), sendo um seco, com baixa precipitação e outro chuvoso, com intensa precipitação pluvial, se fazendo necessário, portanto nos períodos de estiagem, a adoção de complementação hídrica nas lavouras por meio da irrigação, principalmente quando se trata de cultivo de culturas perenes.

Tais cuidados são indispensáveis para garantir que a planta expresse seu potencial genético de produção, e mostre-se economicamente viável a investimentos na manutenção e condução dos pomares. Assim a aplicação superficial do corretivo ao solo por meio de sistemas de irrigação apresenta-se como uma técnica útil para a execução de tal operação na área de cultivo de espécies perenes, mostrando-se 
deste modo como forte aliada da fruticultura possibilitando a realização destes dois tratos culturais em uma única operação, culminando em maior funcionalidade e aproveitamento do sistema de irrigação, menor demanda de mão de obra, maior uniformização da aplicação, menor custo de aplicação, menor circulação de máquinas e consequentemente menor compactação do solo RIBEIRO et al. (1999).

A aplicação do corretivo juntamente com água pode ainda acelerar a reação do corretivo e possibilitar percolação do mesmo no perfil do solo. Entretanto, quando se fala de aplicação de corretivo via água de irrigação deve-se, atentar para os empecilhos passíveis de serem encontrados no momento de sua aplicação, pois a baixa solubilidade das espécies químicas contidas nos corretivos pode ocasionar a sedimentação e em consequência não aplicar uniformemente o produto, ou até mesmo não aplicar, e quando aplicado oferece riscos de entupimento dos emissores (gotejadores, microaspersores) devido ao reduzido diâmetro da secção dos bocais, tornando esta prática difícil ou até mesmo inviável de ser realizada. Embora haja todas estas dificuldades, a técnica é bastante promissora, e a utilização de materiais corretivos mais reativos, com menor granulometria, pode conduzir ao sucesso de sua operacionalização.

Neste contexto objetivou-se com o presente trabalho avaliar a viabilidade da aplicação de produtos corretivos da acidez do solo via água de irrigação, observando-se o coeficiente de uniformidade de Christiasen (CUC), e pressão no final da linha lateral, ambos em função do tempo de aplicação.

\section{MATERIAL E MÉTODOS}

O experimento foi conduzido no Laboratório de Recursos Hídricos do ILES/ULBRA Itumbiara. As avaliações foram realizadas em bancada de ensaios que dispunham de sistema de irrigação (tanque fonte de captação, bomba centrífuga, linhas de recalque, adução e laterais, injetor Venturi, e microaspersores), conforme ilustrado na Figura 2. Os emissores foram fixados dentro de um recipiente (forma para pudim), sendo acoplado à esta, outro recipiente de polietileno, de modo que a lâmina hídrica aplicada pelo microaspersor permanecesse dentro da forma, possibilitando sua coleta por um orifício localizado na parte inferior da mesma, conforme pode ser observado na Figura 1.

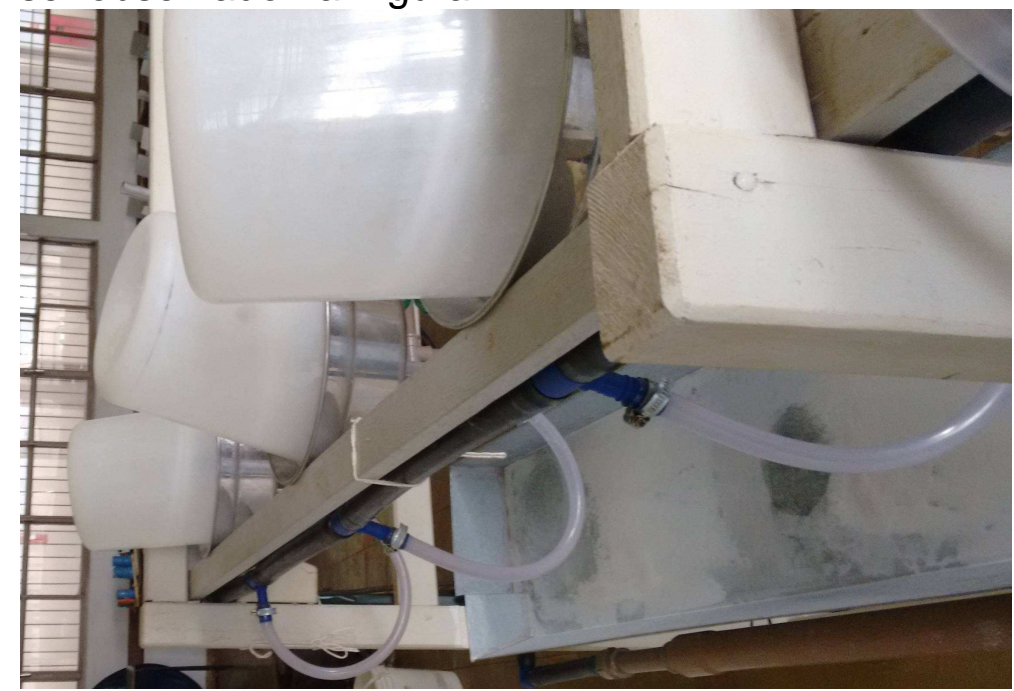

FIGURA 1- Bancada de ensaios após aplicação de cal hidratada.

Fonte: (CARDOSO, 2014). 


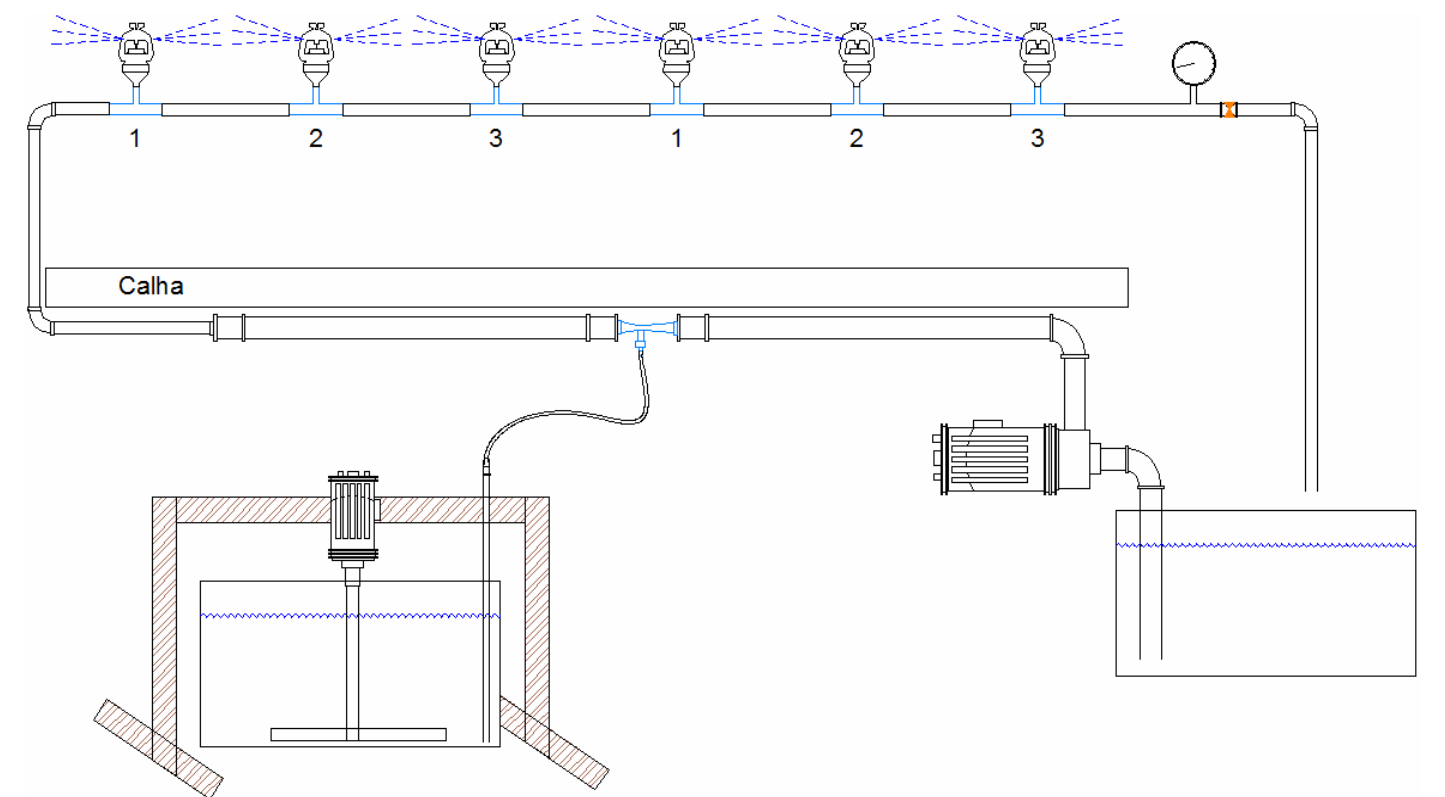

FIGURA 2- Disposição geral do sistema de irrigação.

Fonte: (CARDOSO, 2014a)

Os produtos corretivos foram diluídos em água no tanque da centrifuga, um por vez, formando uma solução de densidade igual a $0,02 \mathrm{Kg} \mathrm{L}^{-1}$. Na sequência foram injetados ao sistema de irrigação por meio de um injetor Venturi. Ao longo da linha de irrigação foram dispostos seis microaspersores de vazão igual a $35 \mathrm{~L} \mathrm{~h}^{-1}$, sendo que os três primeiros constituíam uma repetição e os três últimos constituíam outra repetição.

Foi empregado delineamento experimental inteiramente casualizado em esquema fatorial $4 \times 5$ (4 Corretivos $\times 5$ Tempos de Coleta), totalizando 20 parcelas, sendo cada parcela constituída por três microaspersores. Os tratamentos constituíram da aplicação de calcário sólido, calcário líquido, cal hidratada, e testemunha "água", considerando-se cinco momentos de amostragem, início da aplicação, 30, 60, 90, e 120 minutos após o início

As amostragens foram realizadas durante o funcionamento e injeção do produto no sistema de irrigação, sendo determinada a vazão de cada um dos seis microaspersores, e a cada coleta, era aferida a pressão no final da linha principal. Estes procedimentos foram repetidos por cinco vezes (Inicio, após 30, 60, 90, e 120 minutos), para cada tipo corretivo (calcário sólido, calcário líquido, cal hidratada, e testemunha "água").

Os dados obtidos foram submetidos à fórmula do coeficiente de uniformidade de Christiansen "CUC" que é entre outros, um dos métodos mais utilizados para se aferir a uniformidade de aplicação proporcionada por um sistema de irrigação FRIGO et al. (2013), obtendo-se a eficiência de aplicação do sistema. MERRIAN \& KELLER (1978) propõem uma metodologia de coleta para execução do teste em sistemas de irrigação localizados, o qual se consiste em medir a vazão em quatro pontos ao longo da linha lateral, sendo estes, o primeiro emissor, os emissores situados a $1 / 3$ e $2 / 3$ da linha lateral, e o ultimo emissor, nos quais se afere a vazão e submete-se os valores à equação matemática do coeficiente de Christiansen, conforme a aplicada por LAMBERT (2009), quando estudava o efeito de laminas de irrigação na cultura do cafeeiro, disposta a seguir: 
$C U C=100 \cdot\left[1-\frac{\sum_{i=1}^{n}|q i-\bar{q}|}{n \cdot \bar{q}}\right] \quad($ Equação 1$)$
Em que:

$$
\begin{aligned}
& q i \text { - Vazão do i-ésimo emissor }\left(\mathrm{L} \mathrm{h}^{-1}\right) ; \\
& \bar{q} \text { - Vazão média dos emissores }\left(\mathrm{L} \mathrm{h}^{-1}\right) ; \\
& n \text { - Número de emissores. }
\end{aligned}
$$

Aplicando-se as condições do experimento em pauta, foi considerado no desenvolvimento da fórmula que cada linha de irrigação possuía três emissores, utilizando-se a vazão de todos eles para fins de cálculo.

Os dados de pressão e os obtidos pelo desenvolvimento da fórmula de Christiansen (CUC) foram submetidos à análise de variância em nível de $1 \%$ de probabilidade por meio do software ASSISTAT de SILVA \&AZEVEDO (2009) e quando significativas submetidas à análise de regressão polinomial.

\section{RESULTADOS E DISCUSSÃO}

Com base nos resultados obtidos nas análises de variância para a variável CUC (Tabela 1), observou-se que não houve diferença significativa entre os tratamentos, indicando que mesmo os tratamentos que continham algum tipo de corretivo dissolvido na água aplicada, apresentaram condições estatisticamente semelhantes às apresentadas pela testemunha, água sem nenhum tipo de soluto.

TABELA 1- Resumo da Análise de Variância do Coeficiente de Uniformidade de Christiansen "CUC" (\%) para aplicação de calcário sólido, calcário líquido, cal hidratada, e água, em função do período de aplicação.

\begin{tabular}{cccccc}
\hline \multirow{2}{*}{$\begin{array}{c}\text { Causas } \\
\text { Variação }\end{array}$} & GL & $\begin{array}{c}\text { Calcário } \\
\text { Sólido }\end{array}$ & $\begin{array}{c}\text { Calcário } \\
\text { Líquido }\end{array}$ & Cal Hidratada & Água \\
\hline Períodos & 4 & $0,5538^{\text {ns }}$ & $0,0199^{\text {ns }}$ & $0,1317^{\text {ns }}$ & $0,0917^{\text {ns }}$ \\
Reg. Linear & 1 & $0,0045^{\text {ns }}$ & $0,0328^{\text {ns }}$ & $0,0120^{\text {ns }}$ & $0,1264^{\text {ns }}$ \\
$\begin{array}{c}\text { Reg. } \\
\text { Quadrática }\end{array}$ & 1 & $0,2603^{\text {ns }}$ & $0,0072^{\text {ns }}$ & $0,2508^{\text {ns }}$ & $0,0034^{\text {ns }}$ \\
Resíduo & 5 & $0,9339^{\text {ns }}$ & $0,4730^{\text {ns }}$ & $0,3806^{\text {ns }}$ & $0,1263^{\text {ns }}$ \\
\hline CV $(\%)$ & & 0,98 & 0,69 & 0,62 & 0,36 \\
\hline
\end{tabular}

ns-Não Significativo.

Nas médias dos Coeficientes de Uniformidade de Christiansen descritos na Tabela 1, é possível observar que os solutos adicionados à água de irrigação não interferiram na uniformidade de aplicação do sistema, uma vez que os tratamentos constituídos por Calcário Sólido, Calcário Líquido ou Cal Hidratada apresentaram ENCICLOPÉDIA BIOSFERA, Centro Científico Conhecer - Goiânia, v.13 n.24; p.1083 
valores de CUC bastante similares aos da Testemunha "Água" (Tabela 2), os quais de acordo com KELLER (2009) citado por FRIGO et al. (2013) atingiram eficiência considerada excelente.

TABELA 2- Resultados médios dos coeficientes Coeficiente de Uniformidade de Christiansen (CUC em \%) em função do tempo para cada tipo de corretivo aplicado.

\begin{tabular}{cccccc}
\hline Tipos de & \multicolumn{5}{c}{ Tempo após Início da Aplicação $(\mathbf{m i m})$} \\
\cline { 2 - 6 } Corretivos & Início & 30 & 60 & 90 & 120 \\
\hline Calcário Sólido & 99,315 & 97,935 & 99,045 & 98,985 & 98,865 \\
Calcário & 98,945 & 99,045 & 98,995 & 99,210 & 98,870 \\
$\quad$ Líquido & & 98,890 & 99,205 & 98,855 & 99,440 \\
Cal Hidratada & 99,300 & 99,385 & 99,160 & 99,520 & 99,035 \\
$\quad$ Água & 99,500 & 990 &
\end{tabular}

Em experimento indicativo de alternativas para a diminuição da acidificação do bulbo molhado na cultura do citros, FORATTO (2012) atestou a ausência de problemas na aplicação de cal hidratada via sistema de gotejo, com solução de densidade igual a $7 \mathrm{~g} \mathrm{~L}^{-1}$ durante o período de avaliação de dois anos, apresentando ainda, valores de CUC e CUD classificados como excelente.

Tais aspectos revelam que é possível a aplicação de produto corretivo da acidez do solo via água de irrigação. No entanto deve-se salientar que as densidades " $\rho$ " das soluções adotadas neste experimento $\left(0,02 \mathrm{Kg} \mathrm{L}^{-1}\right)$, foram consideravelmente baixas, deixando dúvidas sobre o tempo necessário para se aplicação as quantidades necessárias para a ocorrência da efetiva neutralização da acidez do solo.

Em um cálculo rápido é possível simular uma situação similar às frequentemente observadas no campo, nas quais para adequar solos distróficos às condições de cultivo, se faz necessária a aplicação de algum tipo de corretivo. A seguir é ilustrada uma situação que estima o tempo necessário para se aplicar por meio da irrigação, as quantidades de corretivos geralmente recomendados: Considerando um solo distrófico, com saturação de bases "V" correspondente a

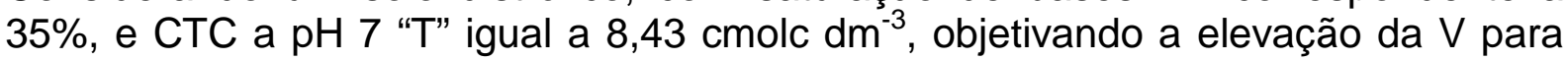
$60 \%$, e adotando-se o método proposto pela Embrapa, abordado por SOUSA E LOBATO (2004), obtém-se uma necessidade de aplicação de $2107,5 \mathrm{~kg} \mathrm{~h}^{-1}$ de corretivo com PRNT de 100\%. Considerando um sistema Venturi que injeta $330 \mathrm{~L} \mathrm{~h}^{-}$ ${ }^{1}$, seriam necessários 13,3 dias de aplicação, os quais adotando-se turno de rega fixo, onde o sistema de irrigação funciona 4 dias na semana, corresponderiam a um tempo estimado de 3 semanas, 1 dia, 7 horas e 12 minutos, para a completa aplicação.

Logo nota-se que nestas concentrações, seriam necessários vários dias para a conclusão da aplicação do corretivo, mostrando-se como ponto negativo à técnica.

No entanto, mesmo com este empecilho esta técnica ainda se mostra com potencial muito promissor, uma vez que evitaria a entrada de máquinas na área do pomar, com isso a redução da produtividade e o aumento dos níveis de erosão, já que segundo SEIXAS \& OLIVEIRA JUNIOR (2001) a circulação de máquinas nas áreas de cultivo promove a compactação do solo, ainda segundo FONTES (2000) o corte excessivo das raízes ocasionado pela gradagem, pode ocasionar prejuízos consideráveis às plantas, e que em resposta a isso, a planta poderá direcionar parte 
de suas reservas para a recuperação do seu sistema radicular, ocasionando diretamente o detrimento à produção de frutos

Todos esses aspectos reforçam o potencial da aplicação do corretivo via água de irrigação, que apesar da demora, apresentam benefícios bastante atrativos, que contribuem para melhores produtividades, além de economizar o que seria gasto pela operação mecanizada, e ainda pode em função da carga hidráulica aplicada e do manejo adotado, promover a incorporação do corretivo ao solo pela lixiviação, acelerando a reação dos produtos no meio edáfico por sua permanência constante em meio úmido.

Outra possibilidade para viabilizar ainda mais sua aplicação seria o aumento da densidade da solução e/ou considerar a aplicação em um percentual da área ao invés de aplicar em área total, mas estes são pontos a serem estudados mais afundo, demandando investigação mais peculiar e específica.

FORATTO (2012) chama a atenção para a colocação de diversos autores que atentam para os problemas de entupimento frequentemente observados em sistemas de fertirrigação, devido à natureza física e química bastante grosseira e com tendência à precipitação dos produtos utilizados implicando na obstrução dos emissores sendo, portanto, recomendado o acompanhamento das vazões dos emissores e das pressões nas linhas de irrigação.

SILVA et al. (2012) afirmam que a pequena área de passagem de água dos emissores é característica inerente à irrigação localizada, e que em função desse pequeno diâmetro a obstrução dos emissores é um dos maiores problemas da fertirrigação, no entanto, o que pôde ser observado foi que em aplicação de até 120 mim, mesmo com a adição dos corretivos à água aplicada, a uniformidade de aplicação manteve-se elevada.

Observando os quadrados médios das análises de variância dos índices de pressão (Tabela 3), nota-se que para ambos os corretivos de acidez aplicados não há diferença significativa de sua aplicação ao logo do tempo, exceto cal hidratada, que apresentou diferença significativa ao nível de $1 \%$ de probabilidade, indicando a ocorrência de variação de pressão ao longo do tempo.

TABELA 3- Resumo da Análise de Variância da pressão ao final da linha (mca) para aplicação de calcário sólido, calcário líquido, cal hidratada, e água, em função do período de aplicação.

\begin{tabular}{cccccc}
\hline $\begin{array}{c}\text { Causas } \\
\text { Variação }\end{array}$ & GL & $\begin{array}{c}\text { Calcário } \\
\text { Sólido }\end{array}$ & $\begin{array}{c}\text { Calcário } \\
\text { Líquido }\end{array}$ & Cal Hidratada & Água \\
\hline Períodos & 4 & $0,0000^{\mathrm{ns}}$ & $0,0000^{\mathrm{ns}}$ & $0,5000^{\mathrm{ns}}$ & $0,0000^{\mathrm{ns}}$ \\
Reg. Linear & 1 & $0,0001^{\mathrm{ns}}$ & $0,0001^{\mathrm{ns}}$ & $1,8000^{* *}$ & $0,0000^{\mathrm{ns}}$ \\
$\begin{array}{c}\text { Reg. } \\
\text { Quadrática }\end{array}$ & 1 & $0,0000^{\mathrm{ns}}$ & $0,0000^{\mathrm{ns}}$ & $0,0000^{* *}$ & $0,0000^{\mathrm{ns}}$ \\
Resíduo & 5 & $0,0002^{\mathrm{ns}}$ & $0,0002^{\mathrm{ns}}$ & $0,1042^{\mathrm{ns}}$ & $0,0001^{\mathrm{ns}}$ \\
\hline $\mathrm{CV}(\%)$ & & 0,17 & 0,19 & 4,30 & 0,14 \\
\hline
\end{tabular}

${ }^{*}$ Significativo a $1 \%$ de probabilidade, pelo teste de $\mathrm{F}$; ns-Não Significativo.

Tratando de conceitos característicos da hidráulica GOMES et al. (2008) apontam em sua revisão que à medida que se restringe a secção de passagem de ENCICLOPÉDIA BIOSFERA, Centro Científico Conhecer - Goiânia, v.13 n.24; p.1085 
um fluído em alguns pontos de saída, o que nas condições deste experimento pode ser ocasionado pela sedimentação de corretivo nas linhas de passagem, pode-se ocasionar o aumento de pressão no interior do duto, pois a força exercida sobre esses pontos de saída, que funcionam como "alívio" do sistema, será redistribuída para as superfícies adjacentes. Assim analisando a "Tabela 3" nota-se que dos corretivos avaliados, a cal hidratada apresenta maior disposição à precipitação e sedimentação, uma vez que em período de avaliação de até 120 minutos, ocasionou leve aumento de pressão na tubulação.

\section{Pressão Cal Hidratada}

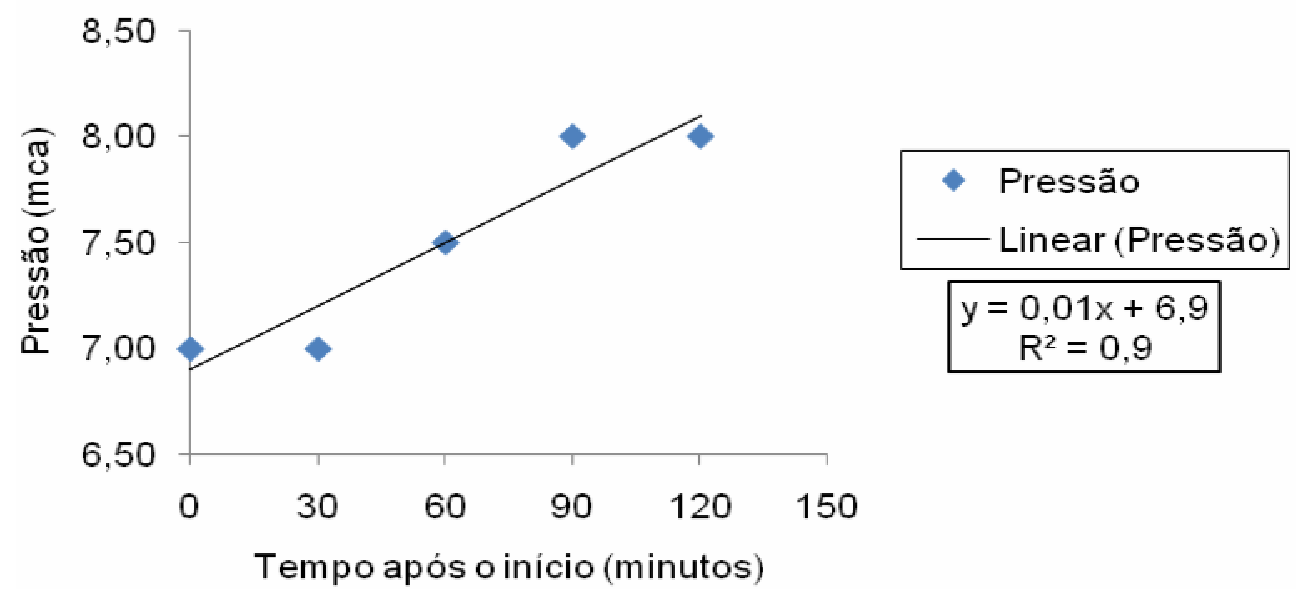

FIGURA 3- Representação gráfica e equação demonstrativa da elevação de pressão ao logo do tempo de aplicação para cal hidratada.

As médias das regressões lineares e quadráticas para a variável pressão (Tabela 3), mostram ainda que não houve variação de pressão ao longo do tempo na aplicação de calcário sólido, calcário líquido, e testemunha "Água", indicando o potencial destes produtos à fertirrigação, uma vez que os dois primeiros apresentam comportamento similar ao controle. As médias das regressões lineares e quadráticas indicam ainda que a aplicação de cal hidratada por longo período de tempo possivelmente acarretaria problemas ao funcionamento do sistema, obstruindo os bocais, o que ocasionaria aumento de pressão e baixa uniformidade de aplicação.

Avaliando a susceptibilidade de micro tubos gotejadores ao entupimento, avaliados em sistema de fertirrigação, ALMEIDA et al. (2013) obtiveram resultados que concordam com os obtidos na aplicação de cal hidratada (Figura 3), onde a uniformidade de distribuição e os coeficientes de variação de vazão iniciam com níveis excelentes, e à medida que o tempo passa estes indicadores vão decrescendo, ao mesmo tempo em que o grau de entupimento obedece a um sentido proporcionalmente ascendente.

Para os sistemas fertirrigados, a garantia da boa uniformidade de aplicação do sistema de irrigação reflete não só na qualidade de distribuição de lâmina hídrica, mas também na boa distribuição do produto adicionado à água, no caso o corretivo. Em trabalho de avaliação da influência da fertirrigação sobre a distribuição de água, SILVA et al. (2012) afirmam que problemas na uniformidade de distribuição dos 
sistemas de fertirrigação, também afetam negativamente a distribuição de água além dos fertilizantes nela dissolvido, proporcionando condições heterogêneas de desenvolvimento do pomar.

No caso de aplicação de corretivo da acidez do solo, significa dar condições diferentes de adsorção de nutrientes, formando várias manchas na uniformidade nutricional do solo, ou seja, a aplicação de corretivo será desuniforme. Em alguns pontos da lavoura poderá ser aplicado mais corretivo que o necessário para manter o pH em condições adequadas ao cultivo, da mesma forma que poderá haver locais onde a quantidade de corretivo aplicado seja irrisória à modificação do pH.

Tendo como base a lei de LIEBIG abordada por RAIJ (2011), a qual tem como ponto fundamental o equilíbrio nutricional disposto aos vegetais, a aplicação de adubo em solo ácido é ineficiente, pois nestas condições os coloides encontram-se ocupados por $\mathrm{Al}^{+3}$. Estas informações nos levam a entender que sob baixa uniformidade de distribuição, o manejo da adubação não atingiria os resultados esperados, ficando claro que o controle da uniformidade de aplicação dos sistemas de fertirrigação é um ponto que merece atenção peculiar.

\section{CONCLUSÃO}

Nas condições deste experimento conclui-se que é possível aplicar corretivo da acidez do solo com densidade de $0,02 \mathrm{Kg} \mathrm{L}^{-1}$ via água de irrigação sem prejudicar a uniformidade de aplicação "CUC" em período de até 120 min.

As soluções constituídas de cal hidratada apresentam forte tendência à sedimentação e precipitação, podendo causar entupimento e aumento de pressão na tubulação.

A aplicação das quantidades recomendadas de corretivos por meio da água de irrigação, em concentrações de $0,02 \mathrm{Kg} \mathrm{L}^{-1}$, demanda muito tempo, sendo necessários novos estudos para melhor compreensão e aperfeiçoamento desta técnica.

\section{AGRADECIMENTOS}

À coordenação de Agronomia do ILES-ULBRA Itumbiara, pelo auxílio no desenvolvimento do estudo.

\section{REFERÊNCIAS}

ALMEIDA, C. D.G. C.; SILVA, S. S.; ALBUQUERQUE FILHO, J. A. C.; SILVA, Ê. F. de $\mathrm{F}$. Susceptibilidade ao entupimento de microtubos gotejadores sob fertirrigação. Irriga. v.18, n.3, p.454-470, julho-setembro, 2013. Disponível em: $<$ http://irriga.fca.unesp.br/index.php/irriga/article/view/607/407>. http://dx.doi.org/10.15809/irriga.2013v18n3.

CARDOSO, J. A. E. Bancada de ensaios após aplicação de cal hidratada. 2014. 1 fotografia, color., $6,70 \mathrm{~cm} \times 9,77 \mathrm{~cm}$. Coleção particular.

CARDOSO, J. A. E. Disposição geral do sistema de irrigação. 2014a. 1 ilustração, $6,70 \mathrm{~cm} \times 9,77 \mathrm{~cm}$. Coleção particular.

FONTES, H. R. Aspectos relacionados com a utilização da gradagem do solo nas entrelinhas de plantio de coqueiro. Aracaju: Embrapa Tabuleiro Costeiro, 2000. (Comunicado Técnico, 39). 3p. 
FORATTO, L. C. Alternativas para a diminuição do bulbo molhado na cultura do citros. 2012. 89f. Tese (Doutorado em Agronomia / Irrigação e Drenagem) Faculdade de Ciências Agronômicas, UNESP, Botucatu, 2012.

FRIGO, J. P.; VILAS BOAS, M.; FRIGO, E. P.; HERMES, E.; TESSARO, E. Irrigação diurna e noturna em sistema de aspersão convencional em Palotina-PR. Irriga. v.18, n.2, p.318-327, abril-junho, 2013. Disponivel em: <http://revistas.fca.unesp.br/index.php/irriga/article/view/545/370>. doi: http://dx.doi.org/10.15809/irriga.2013v18n2p318.

GOMES, M. R.; ANDRADE, M.; FERRAZ, F. Apostila de hidráulica. Santo Amaro: CEFET-BA, 2008. (Apostila, 1). 65p.

LAMBERT, R. A. Laminas de irrigação por gotejamento na cultura do cafeeiro. 2009. 65f. Dissertação (Mestrado em Agronomia) - Universidade Federal de Uberlândia, UFU, Uberlândia, 2009.

MERRIAN, J. L. e KELLER, J. Farm Irrigation system evaluation: a guide for management. Logan; Utah State University, 1978, 271p.

PESSONI, P. T. Calagem e gessagem na cultura da soja e do triticale. 2009. 93f. Dissertação (Mestrado em Agricultura tropical e subtropical / Gestão de Recursos Agroambientais) - Instituto Agronômico, IAC, Campinas, 2009.

RAIJ, B. V. Fertilidade do solo e manejo de nutrientes. Piracicaba: Iternational Plant Nutrition Institute, 2011. 420p.

RIBEIRO, A. C.; GUIMARÃES, P. T. G.; ALVARES, V. H. CFSEMEG - Comissão de Fertilidade de Solo do Estado de Minas Gerais. Recomendações para uso de corretivos e fertilizantes em Minas Gerais. 5. Aproximação. Viçosa, MG, 1999.

SEIXAS, F.; OLIVEIRA JUNIOR, E. Compactação do solo devido ao trafego de máquinas de colheita de madeira. SCIENTIA FORESTALIS. n.60, p.73-87, 2001. Disponível em: <http://www.ipef.br/publicacoes/scientia/nr60/cap06.pdf>. doi:

SILVA, F. A. S.; AZEVEDO, C. A. V. Principal Components Analysis in the Software Assistat-Statistical Attendance. In:WORLD CONGRESS ON COMPUTERS IN AGRICULTURE, 7, Reno-NV-USA: American Society of Agricultural and Biological Engineers, 2009.

SILVA, V. R.; TEIXEIRA, M. B.; CUNHA, F. N.; OLIVEIRA, R. C.; BASTOS, F. J. C.; RIBEIRO, J. P. T. Influência da fertirrigação na distribuição de aplicação de água. In: I Congresso de Pesquisa e Pós-Graduação do Campus Rio Verde do IF Goiano. 2012, Rio Verde. Anais... Rio Verde: IF Goiano, 2012.

SOUSA, D. M. G.; LOBATO, E. Cerrado: correção do solo e adubação. 2 ed. Brasília: Embrapa, 2004. 